\title{
The Effect of Speciality Designated Core Exercises on Upper Exterimity Posture Structures of Male High School Students
}

\author{
Ercan Gür ${ }^{1}$, Gürkan Tokgöz ${ }^{1}$ \\ ${ }^{1}$ Faculty of Sport Sciences, Firat University, Turkey \\ Correspondence: Ercan Gür, Faculty of Sport Sciences, Firat University, Turkey
}

Received: January 15, 2019

Accepted: January 29, 2019

Online Published: January 30, 2019

doi:10.11114/jets.v7i3S.4008

URL: https://doi.org/10.11114/jets.v7i3S.4008

\begin{abstract}
The aim of this study is to research on the effect of core exercises on the upper extremity posture structure of young individuals. 30 male students between 16 to 18 years old studying in a high school in the province of Elazig and not doing regular sport volunteered for this study. The participants were randomly divided into two as the subject group and the control group; each group was formed with 15 people. Out of the groups formed, the subject group carried out specially designated core exercises for 8 weeks, and for 3 days each week. The control group didn't do any work; they continued their normal lives. Before and after the study, the height, weight, body mass index, bodily fat percentage, upper extremity posture(from the front, back, right and left)of the subject and control groups formed were measured and the Adams(stoop) test was applied. The data obtained were analyzed through SPSS 22.0 statistical program. For the in-group and intergroup comparisons, independent samples $\mathrm{T}$ test and paired samples $\mathrm{T}$ test were used. After the statistical analysis, during the initial and subsequent test comparisons of the control group, no difference was detected in measurements apart from the one for shoulders from the anterior side. Statistical differences were determined for a lot of values during the comparison of the initial and subsequent test results of the subject group and during the comparison of the differences between the initial and subsequent test results of the subject and control group. In conclusion, it was determined that core exercises made a positive impact on the upper extremity posture structures of male individuals between the ages of 16 and 18 .
\end{abstract}

Keywords: core exercises, high school student, posture, upper extremity

\section{Introduction}

Posture is generally defined as the stance of the body (Karakus, Seydi, Kilinc, 2006). In the definition in 1947 belonging to American Orthopedy Academy Committee of Posture; posture was defined as the balanced and smooth arrangement of the components of the skeleton in a way that they can protect the supporting structures of the body from damage and disablement that can be called on highest degree (Calliet, 1994). Posture varies depending on nationality, race, hobbies, gender, occupation and the bodily type of the individual. As long as the essential support system of the body is proper, a standard posture may develop for the purpose of forming, sustaining and adjusting the posture (Karakus, Seydi \& Kilinc, 2006). The good mood of the individual, proper hygiene conditions, normal sleep, doing sport in clean and open air as much as possible, good diet are the main elements that enable the development of muscles and postural stance (Karakus, Seydi, Kilinc, 2006). As the result of the research, that there are postural differences among sport branches was determined (Uetake \& Ohtsuki, 1993). Stance habits resulting from movement variety of trainings done beginning from small ages and stances during trainings affect posture. Training overload applied on a particular region affects the normality of postural structure. For instance, dominant arm technique trainings in basketball cause the weakening of the side that is not dominant. In such basketball players, shoulder lowness in the dominant side is observed (Kilinc, 1997). Different training varieties influence the physical structures of sportspeople (Elliot, 1998). It is also observed that intense trainings carried out at small ages influence posture, too (Wojtys, Ashton-Miller, Huston, Moga, 2000).

Posture analysis is carried out for the purpose of determining the postural imperfections in the patient and methods to treat them, also of warning the patient by determining the imperfections that might form in the future. Posture analysis is carried out in three ways; lateral analysis, posterior and anterior analyses (Ecerkale, 2006).

A training program that an individual applies with his or her own bodily weight for the purpose of strengthening the 
deep muscles that hold the spine in balance, muscles in the abdominal region and the waist region is called core exercise (Atant, 2013). A core training may be defined as a kind of specially-prepared training aimed at a particular muscle or a particular muscle group. Core muscles comprise back and waist muscles, abdominal upper and lower muscles. They are responsible for the strength transfer between the two halves of the body thought of upper and lower ones (Figg, 2005). Core exercises provide a wide fitness program that will help the individual feel good, look good, move strongly and be aesthetic and completes all the elements specified and brings them all together (Brungardt, Brungardt, brungardtm, 2006).

\section{Method}

\subsection{Study Group}

Volunteer students between the ages of 16 and 18, studying in a high school in Elazig randomly determined, not doing sport regularly were included in this study. The subject and control groups were formed by random selection. All the measuarements were carried out under the control of an expert orthopedist. Before the study, the required permission was obtained from the directorate of the school where the study was going to be carried out and from the Directorate of National Education. Also, because the participants were younger than 18 years of age, a form for being a volunteer participant was examined and signed by their parents.

\subsection{Working Schedule}

The control group continued their normal lives for a period of eight weeks; they didn't do any special exercise. The subject group carried out the core exercises specified in the program regularly for a period of eight weeks on Monday, Wednesday and Friday under the supervision of a researcher. They carried out each action for 15 seconds in the $1^{\text {st }}$ and $2^{\text {nd }}$ weeks, for 20 seconds in the $3^{\text {rd }}$ and $4^{\text {th }}$ weeks, for 25 seconds in the $5^{\text {th }}$ and $6^{\text {th }}$ weeks and for 30 seconds in the $7^{\text {th }}$ and $8^{\text {th }}$ weeks. Before the work, warm-up exercises were done and after it, cooling exercises were. Those who couldn't participate in the group work for any reason did the work that they hadn't been able to do individually, under the supervision of a researcher afterwards.

\subsection{Measurements and Tests}

\subsubsection{Anthropometric Measurements}

The bodily weights of the participants were measured with naked feet and with shorts through digital scales whose maximum weight capacity is $150 \mathrm{kgs}$ and measuring range is $0,1 \mathrm{kgs}$. The measurements were made separately before and after the study and recorded in kgs. The measurement of height was made through a measuring stick immobilised on a flat wall. The participants stood in front of the measuring stick with naked feet, the measurements were made above their heads and recorded in cms (Gökhan, Aktaş, Aysan, 2015). The body mass index and bodily fat percentage were measured by a body analyzer.

\subsubsection{Posture Analysis}

The posture analysis of the participants was made through a posture analysis program called "Posturescreen" (Normand, Martin, 2007), (Hopkins, breannacristineberry, 2014). The photographs of the participants in this study with naked feet and with shorts were taken from anterior, posterior, right and left directions and the proximity of them to the ideal posture was determined in $\mathrm{cms}$ by the program. Through this program, the analysis and comparison before and after the study of the head, shoulder, rib cage and hip stance were carried out. 




Figure 1. Posture Analysis from the Anterior Direction

\section{Exam for $\quad$ performed on 14.06.2016}

\begin{tabular}{l} 
Right Lateral View \\
Anterior View Posture Displacements \\
\hline |
\end{tabular}

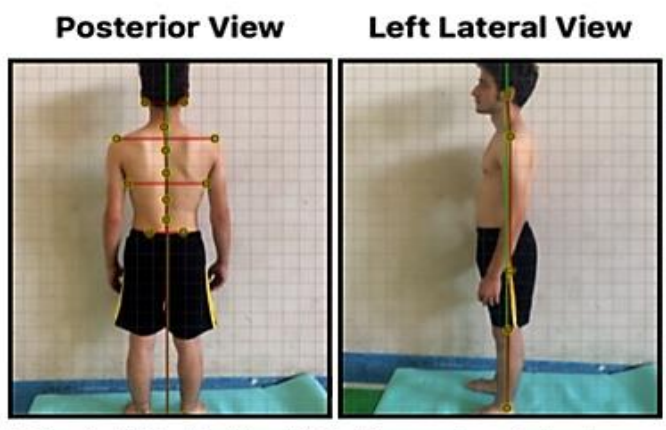

Estimated Effective Head Weight secondary to head vs. shoulder posture is $7,7 \mathrm{kgs}$ instead of $4,8 \mathrm{kgs}$

Averaged Lateral Postural Displacements

\begin{tabular}{|c|c|c|c|c|}
\hline & Head & Shoulder & Mlp/Pevtis & Knee \\
\hline \begin{tabular}{|l|} 
Lateral \\
Translations \\
\end{tabular} & $\begin{array}{l}1,59 \mathrm{~cm} \\
\text { onterior } \\
\end{array}$ & $\begin{array}{l}1,57 \mathrm{~cm} \\
\text { anterior }\end{array}$ & $\begin{array}{l}1,19 \mathrm{~cm} \\
\text { anterior }\end{array}$ & $\begin{array}{l}1.35 \mathrm{~cm} \\
\text { oncerior }\end{array}$ \\
\hline \begin{tabular}{|l|} 
Lateral \\
Angulations
\end{tabular} & $4,74^{\circ}$ flexed & $1,3 r^{*}$ flexed & $0,92^{*}$ flexed & $1,9 r$ flexed \\
\hline
\end{tabular}

\section{Posture Displacements}

\begin{tabular}{|c|c|c|c|c|}
\hline $\begin{array}{l}\text { Body } \\
\text { Region }\end{array}$ & $\begin{array}{l}\text { Ponterior } \\
\text { Transtations }\end{array}$ & $\begin{array}{l}\text { Posterior } \\
\text { Angulations }\end{array}$ & $\begin{array}{l}\text { Cuteral } \\
\text { Trantibitions }\end{array}$ & $\begin{array}{l}\text { Latersl } \\
\text { Angulotions }\end{array}$ \\
\hline Head & $\begin{array}{c}0,49 \\
\text { cmleft }\end{array}$ & $\sigma^{\circ}$ & $\begin{array}{l}1,24 \mathrm{~cm} \\
\text { anterior }\end{array}$ & $\begin{array}{l}3,74^{\circ} \\
\text { flexed }\end{array}$ \\
\hline Shoulder & $\begin{array}{c}0.48 \\
\text { cmleft }\end{array}$ & 0 & $\begin{array}{c}0.18 \mathrm{~cm} \\
\text { posterior }\end{array}$ & $0^{\circ}$ \\
\hline Ribcage & $\begin{array}{c}0,21 \mathrm{~cm} \\
\text { right }\end{array}$ & $n / a$ & $\mathrm{~N} / \mathbf{a}$ & $\mathrm{N} / \mathrm{a}$ \\
\hline Hip/Pelvis & $\begin{array}{l}0,35 \\
\text { cmleft }\end{array}$ & $2,0^{*}$ left & $\begin{array}{c}0,72 \mathrm{~cm} \\
\text { posterior }\end{array}$ & $\begin{array}{c}1,55^{\circ} \\
\text { extended }\end{array}$ \\
\hline Knee & $n / a$ & $\mathrm{~N} / \mathrm{a}$ & $\begin{array}{c}0,55 \mathrm{~cm} \\
\text { posterior }\end{array}$ & $0^{\circ}$ \\
\hline T1-T4 & $\begin{array}{c}0,55 \\
\text { cmleft }\end{array}$ & $3,0^{\circ}$ left & $n / a$ & $\mathrm{~N} / \mathrm{a}$ \\
\hline T4-T8 & $\begin{array}{c}0,28 \\
\text { cmleft }\end{array}$ & $1,5^{*}$ left & $\mathrm{N} / \mathrm{a}$ & $\mathrm{N} / \mathrm{a}$ \\
\hline T8-T12 & $\begin{array}{c}0,07 \\
\text { cmleft }\end{array}$ & $\sigma^{\circ}$ & $n / a$ & $\mathrm{~N} / \mathrm{a}$ \\
\hline$T 12-13$ & $\begin{array}{c}0,07 \mathrm{~cm} \\
\text { right }\end{array}$ & $\sigma$ & $\mathrm{n} / \mathrm{a}$ & $\mathrm{Na}$ \\
\hline $\begin{array}{l}\text { L3-Mid } \\
\text { PSIS }\end{array}$ & $\begin{array}{c}0,10 \\
\text { cmleft }\end{array}$ & $1,0^{*}$ left & $N / a$ & $n / a$ \\
\hline Total & $2,60 \mathrm{~cm}$ & $7,6^{*}$ & $2,70 \mathrm{~cm}$ & $5,3^{*}$ \\
\hline
\end{tabular}

Figure 2. Posture Analysis Results from Four Sides 


\section{PostureScreen Comparison Report for}

ANTERIOR VIEW
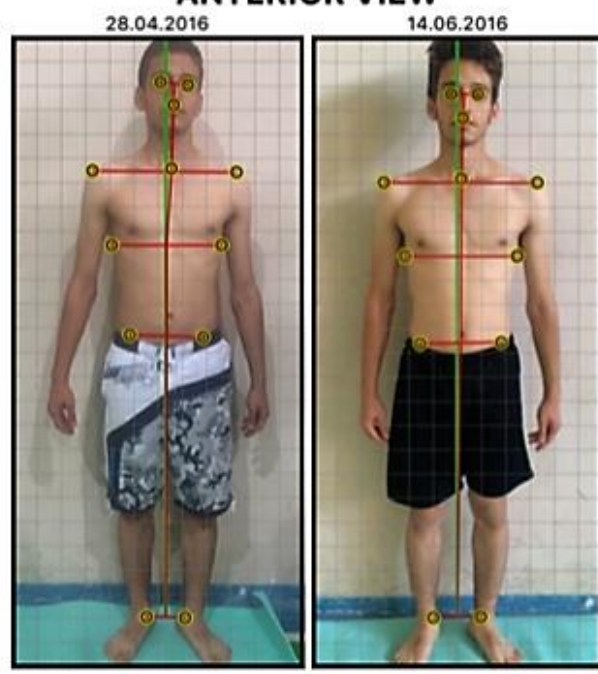

POSTERIOR VIEW
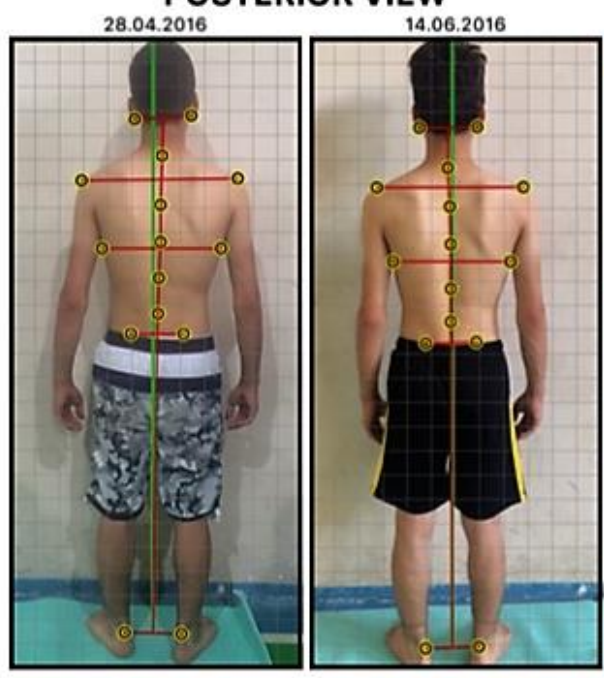

performed on 28.04.2016 and 14.06.2016

\section{Posture Displacements}

\begin{tabular}{|l|c|c|c|c|}
\hline Body Region & \multicolumn{2}{|c|}{ Anterior Translations } & \multicolumn{2}{c|}{ Anterior Angulations } \\
\hline & 28.04 .2016 & 14.06 .2016 & 28.04 .2016 & 14.06 .2016 \\
\hline Head & $0,73 \mathrm{~cm}$ left & $0,83 \mathrm{~cm}$ left & $6,4^{*}$ left & $0^{*}$ \\
\hline Shoulder & $1,35 \mathrm{~cm}$ left & $0,07 \mathrm{~cm}$ left & $0^{*}$ & $0^{*}$ \\
\hline Ribcage & $0,03 \mathrm{~cm}$ right & $0,07 \mathrm{~cm}$ left & $N / \mathrm{a}$ & $\mathrm{N} / \mathrm{a}$ \\
\hline Hip/Pelvis & $0,25 \mathrm{~cm}$ left & $0,99 \mathrm{~cm}$ left & $1,8^{*}$ left & $0^{\circ}$ \\
\hline Total & $2,36 \mathrm{~cm}$ & $1,96 \mathrm{~cm}$ & $8,2^{*}$ & $0,0^{*}$ \\
\hline
\end{tabular}

\section{Posture Displacements}

\begin{tabular}{|l|c|c|c|c|}
\hline Body Region & \multicolumn{2}{|c|}{ Posterior Transtations } & \multicolumn{2}{c|}{ Posterior Angulations } \\
\hline & 28.04 .2016 & 14.06 .2016 & 28.04 .2016 & 14.06 .2016 \\
\hline Head & $0,93 \mathrm{~cm}$ right & $0,49 \mathrm{~cm}$ left & $3,6^{*}$ left & $0^{*}$ \\
\hline Shoulder & $0,49 \mathrm{~cm}$ left & $0,48 \mathrm{~cm}$ left & $0^{*}$ & $0^{*}$ \\
\hline Ribcage & $1,21 \mathrm{~cm}$ right & $0,21 \mathrm{~cm}$ right & $N^{*}$ & $N^{\circ}$ \\
\hline Hip/Pelvis & $1,12 \mathrm{~cm}$ left & $0,35 \mathrm{~cm}$ right & $0^{*}$ & $2,0^{*}$ left \\
\hline T1-T4 & $0,41 \mathrm{~cm}$ right & $0,55 \mathrm{~cm}$ left & $1,8^{*}$ left & $3,0^{*}$ right \\
\hline T4-T8 & $0 \mathrm{~cm}$ & $0,28 \mathrm{~cm}$ left & $0^{*}$ & $1,5^{*}$ right \\
\hline T8-T12 & $0,48 \mathrm{~cm}$ right & $0,07 \mathrm{~cm}$ left & $2,8^{*}$ left & $0^{*}$ \\
\hline T12-43 & $0,28 \mathrm{~cm}$ right & $0,07 \mathrm{~cm}$ right & $1,6^{*}$ left & $0^{*}$ \\
\hline L-Mid PSIS & $0,21 \mathrm{~cm}$ right & $0,10 \mathrm{~cm}$ left & $2,1^{*}$ left & $1,0^{*}$ right \\
\hline Total & $5,14 \mathrm{~cm}$ & $2,60 \mathrm{~cm}$ & $11,9^{*}$ & $7,6^{*}$ \\
\hline
\end{tabular}

Figure 3. Posture Comparison Before and After the Study

\subsubsection{Adams Test}

This test is the test of stoop; it is the most effective and the fastest examination method in diagnosing scoliosis. In this test, the individual combines his or her two hands, leans downward in a way that his or her shoulder will be parallel to the ground. The doctor that does the checking checks the kyphosis that forms in the back and at the sides. The doctor determines the angle of the kyphosis in relation to the ground plane with the scoliometer. If the curvature that is known as "Rib Hump Deformity" is more than 10 degrees, the situation needs to be radiologically checked. (Yaman, Onur, Sedat Dalbayrak,2013). The Adams Test was performed on all of the participants before and after the study; the results obtained were recorded in degrees. The participants that got more than 10 degrees were recommended to receive a special examination at a hospital.

\subsection{Analysis of the Data}

In the calculation of the data and in the evaluation of the data calculated, SPSS 22 statistical packaged software was used. Initially, a test of normality was carried out. In the test comparisons of groups before and after the study, Paired-Samples $T$ test ( $t$ test concerning the difference between the arithmetic averages in dependent groups) was carried out. In the initial and subsequent test comparisons between groups, Independent-sample test ( $t$ test in arithmetic averages in independent groups) was used. The confidence range in this study was regarded to be as 0,05 and 0,01 . 


\section{Results}

The data and the statistical findings obtained as the result of our study carried out for the purpose of measuring the effects of the core exercises done for 8 weeks on the upper extremity posture structures of young males are presented in tables below.

Table 3. The Initial and Subsequent Test Comparison of the Subject Group Anthropomethric Measurements

\begin{tabular}{|c|c|c|c|c|c|}
\hline $\begin{array}{l}\text { 16-18Years of } \\
\text { Age Variable } \\
\mathrm{N}: 15\end{array}$ & Initial Test & $\begin{array}{l}\text { Subsequent } \\
\text { test }\end{array}$ & Difference & $\mathrm{T}$ & $\mathrm{P}$ \\
\hline Height & $174,53 \pm 5,52$ & $175,00 \pm 5,22$ & $-0,47$ & $-2,432$ & ,029* \\
\hline Weight & $64,86 \pm 10,08$ & $65,13 \pm 8,66$ & $-0,27$ & $-0,636$ &, 535 \\
\hline Fat Percentage & $15,51 \pm 6,32$ & $13,44 \pm 6,74$ & 2,07 & 6,80 &, $000 * *$ \\
\hline$B m \imath$ & $21,45 \pm 3,10$ & $20,44 \pm 2,95$ & 1,01 & 9,28 &, $000 * *$ \\
\hline
\end{tabular}

During the comparison of the anthropomethric measurements of the subject group before and after the study, an increase of $0,47 \mathrm{cms}$ in the height average, a decrease of $0,27 \mathrm{kgs}$ in the weight average, a decrease of 2,07 in the fat percentage average and a decrease of 1,01 in the average of the body mass index were determined. In the measurements of weight, no statistically significant difference was found. In the measurements of the height, a difference was determined according to the $\mathrm{P}<0,05$ significance level. In the measurements of the fat percentage and body mass index, a difference was determined according to the $\mathrm{P}<0,01$ significance level.

Table 2. The Comparison of the Initial and Subsequent Tests of the Anthropomethric Measurements of the Control Group

\begin{tabular}{llllll}
\hline $\begin{array}{l}\text { 16-18 Years of } \\
\text { Age Variable }\end{array}$ & Initial Test & Subsequent test & $\begin{array}{l}\text { Differen } \\
\text { ce }\end{array}$ & $T$ & $P$ \\
$N: 15$ & & & & \\
\hline Height & $173,60 \pm 4,89$ & $174,00 \pm 4,72$ & $-0,40$ & $-3,055$ &, $009 * *$ \\
Weight & $64,73 \pm 11,701$ & $65,33 \pm 11,424$ & $-0,60$ & $-1,964$ &, 070 \\
Fat Percentage & $15,00 \pm 6,91$ & $14,94 \pm 6,97$ & 0,06 & 0,172 &, 866 \\
$* \mathrm{P}<0,05$ & $21,22 \pm 3,45$ & $21,18 \pm 3,59$ & 0,04 & 0,325 &, 750 \\
\cline { 2 - 2 } & $* * \mathrm{P}<0,01$ & & & &
\end{tabular}

In the comparison of the anthropomethric measurements of the control group before and after the study, an increase of $0,40 \mathrm{cms}$ in the average height, an increase of $0,60 \mathrm{kgs}$ in the average of weight, a decrease of 0,06 in the average of fat percentage and a decrease of 0,04 in the average of the body mass index were determined. At the end of the measurement of height, a difference was statistically determined according to the $\mathrm{P}<0,05$ significance level. No difference was statistically determined in the measurements of the weight, fat percentage and the body mass index. 
Table 3. The Initial and Subsequent Test Comparison of the Measurement of Upper Extremity of the Subject Group

\begin{tabular}{l|lllll}
\hline \begin{tabular}{l} 
16-18 Years of Age Variable \\
\multicolumn{1}{c}{ N:15 }
\end{tabular} & Initial Test & Subsequent Test & Difference & T & P \\
\hline Head from Anterior Side & $0,694 \pm 0,432$ & $0,616 \pm 0,495$ & 0,078 & 0,784 &, 481 \\
Shoulder from Anterior Side & $0,726 \pm 0,407$ & $0,395 \pm 0,498$ & 0,401 & 1,961 &, 070 \\
Rib Cage from Anterior Side & $0,891 \pm 0,687$ & $0,622 \pm 0,633$ & 0,269 & 1,941 &, 073 \\
Hips from Anterior Side & $2,242 \pm 1,201$ & $1,390 \pm 1,023$ & 0,852 & 2,366 &, $033^{*}$ \\
Head from Posterior Side & $1,186 \pm 0,753$ & $0,770 \pm 0,581$ & 0,416 & 2,381 &, $032^{*}$ \\
Shoulder from Posterior Side & $0,500 \pm 0,365$ & $0,362 \pm 0,255$ & 0,138 & 1,295 &, 216 \\
Rib Cage from Posterior Side & $0,892 \pm 0,456$ & $0,320 \pm 0,181$ & 0,572 & 4,295 &, $001^{* *}$ \\
Hips from Posterior Side & $2,060 \pm 1,288$ & $1,256 \pm 0,832$ & 0,804 & 2,387 &, $032^{*}$ \\
Head from Right Side & $4,709 \pm 2,165$ & $2,969 \pm 1,655$ & 1,740 & 3,820 &, $002^{* *}$ \\
Shoulder from Right Side & $3,110 \pm 2,180$ & $2,970 \pm 2,183$ & 0,140 & 0,297 &, 771 \\
Hips from Right Side & $2,789 \pm 1,856$ & $2,162 \pm 1,340$ & 0,627 & 1,583 &, 136 \\
Head from Left Side & $3,351 \pm 2,258$ & $2,104 \pm 1,628$ & 1,247 & 2,939 &, $011^{*}$ \\
Shoulder from Left Side & $2,546 \pm 1,632$ & $1,242 \pm 1,109$ & 1,304 & 3,601 & $0,03 * *$ \\
Hips from Left Side & $2,780 \pm 2,424$ & $1,432 \pm 1,093$ & 1,348 & 2,571 &, $022^{*}$ \\
Scoliometer & $6,466 \pm 2,133$ & $5,600 \pm 1,843$ & 0,866 & 4,516 &, $000^{* *}$ \\
\hline \multicolumn{1}{c}{$* * \mathrm{P}<0,01$} & & & & &
\end{tabular}

$* \mathrm{P}<0,05 \quad * * \mathrm{P}<0,01$

In the comparison of the upper extremity measurements of the subject group before and after the study according to the table, no statistically significant difference is observed in the measurements of the head from the anterior side, the shoulder from the anterior side, the rib cage from the anterior side, the shoulder from the posterior side, the shoulder from the right side and the hips from the right side. In the measurements of the hips from the anterior side, the head from the posterior side, hips from the posterior side, the head from the left side and the hips from the left side, a difference in a positive way was determined according to the $\mathrm{P}<0,05$ significance level. In the measurements of the rib cage from the posterior side, the head from the right side, the shoulder from the left side and the scoliometer, a difference in a positive way was determined according to the $\mathrm{P}<0,01$ significance level.

Table 3.4. The Initial and Subsequent Test Comparison of the Upper Extremity Measurements of the Control Group

\begin{tabular}{l|lllll}
\hline $\begin{array}{c}\text { 16-18 Years of Age Variable } \\
\text { N:15 }\end{array}$ & Initial Test & Subsequent test & Difference & $\mathrm{T}$ & $\mathrm{P}$ \\
\hline Head from Anterior Side & $0,459 \pm 0,468$ & $0,397 \pm 0,252$ & 0,062 & 0,563 &, 582 \\
Shoulder from Anterior Side & $0,472 \pm 0,334$ & $0,896 \pm 0,790$ & $-0,424$ & $-2,687$ &, $018^{*}$ \\
Rib Cage from Anterior Side & $0,582 \pm 0,399$ & $0,784 \pm 0,555$ & $-0,202$ & $-1,862$ &, 084 \\
Hips from Anterior Side & $1,520 \pm 0,720$ & $1,871 \pm 0,533$ & $-0,351$ & $-1,625$ &, 126 \\
Head from Posterior Side & $0,900 \pm 0,723$ & $1,152 \pm 1,042$ & $-0,252$ & $-1,572$ &, 138 \\
Shoulder from Posterior Side & $0,608 \pm 0,449$ & $0,747 \pm 0,503$ & $-0,139$ & $-1,068$ &, 304 \\
Rib Cage from Posterior Side & $0,422 \pm 0,315$ & $0,490 \pm 0,304$ & $-0,068$ & $-0,693$ &, 500 \\
Hips from Posterior Side & $2,384 \pm 1,302$ & $2,790 \pm 1,073$ & $-0,406$ & $-1,265$ &, 227 \\
Head from Right Side & $2,378 \pm 1,077$ & $2,458 \pm 1,092$ & $-0,080$ & $-0,385$ &, 706 \\
Shoulder from Right Side & $3,050 \pm 1,299$ & $3,083 \pm 2,009$ & $-0,033$ & $-0,092$ &, 928 \\
Hips from Right Side & $2,607 \pm 1,796$ & $2,892 \pm 1,769$ & $-0,285$ & $-1,145$ &, 271 \\
Head from Left Side & $1,636 \pm 1,579$ & $2,051 \pm 1,831$ & $-0,415$ & $-1,747$ &, 103 \\
Shoulder from Left Side & $2,203 \pm 2,072$ & $2,852 \pm 2,072$ & $-0,649$ & $-1,671$ &, 117 \\
Hips from Left Side & $1,687 \pm 1,342$ & $2,040 \pm 1,692$ & $-0,353$ & $-0,645$ &, 529 \\
Scoliometer & $6,266 \pm 2,282$ & $6,200 \pm 2,396$ & 0,066 & 0,564 &, 582 \\
* $<0$ P 05 P $<0,01$ & & & & &
\end{tabular}

According to Table 5, in the comparison of the measurements of the upper extremity before and after the study carried out on the control group, a difference was determined only in the measurement of the shoulder from the front according to the significance of $\mathrm{p}<0,05$. In the comparison of the other measurements, no statistically significant difference was found. 
Table 5. The Comparison of Initial and Subsequent Test Differences Concerning Upper Extremity Measurements of the Subject and Control Group

\begin{tabular}{lcllll}
\hline 16-18 Years of Age Variable & $\begin{array}{c}\text { Subject Group } \\
\text { Difference } \\
N: 15\end{array}$ & $\begin{array}{c}\text { Control Group } \\
\text { Difference N:15 }\end{array}$ & Difference & $T$ & $P$ \\
\hline Head from Anterior Side & $0,078 \pm 0,417$ & $0,062 \pm 0,426$ & 0,016 & 0,104 &, 918 \\
Shoulder from Anterior Side & $0,330 \pm 0,653$ & $-0,424 \pm 0,611$ & 0,754 & 3,268 &, $003^{* *}$ \\
Rib Cage from Anterior Side & $0,268 \pm 0,536$ & $-0,201 \pm 0,418$ & 0,469 & 2,676 &, $012^{*}$ \\
Hips from Anterior Side & $0,852 \pm 1,394$ & $-0,351 \pm 0,837$ & 1,203 & 2,865 &, $008^{* *}$ \\
Head from Posterior Side & $0,416 \pm 0,677$ & $-0,252 \pm 0,620$ & 0,668 & 2,821 &, $009^{* *}$ \\
Shoulder from Posterior Side & $0,138 \pm 0,412$ & $-0,140 \pm 0,504$ & 0,278 & 1,651 &, 110 \\
Rib Cage from Posterior Side & $0,572 \pm 0,515$ & $-0,067 \pm 0,376$ & 0,639 & 3,878 &, $001^{* *}$ \\
Hips from Posterior Side & $0,804 \pm 1,304$ & $-0,406 \pm 1,243$ & 1,21 & 2,600 &, $015^{*}$ \\
Head from Right Side & $1,740 \pm 1,764$ & $-0,080 \pm 0,804$ & 1,82 & 3,636 &, $001^{* *}$ \\
Shoulder from Right Side & $0,140 \pm 1,825$ & $-0,032 \pm 1,368$ & 0,172 & 0,293 &, 772 \\
Hips from Right Side & $0,623 \pm 1,529$ & $-0,285 \pm 0,965$ & 0,908 & 1,946 &, 062 \\
Head from Left Side & $1,249 \pm 1,645$ & $-0,415 \pm 0,912$ & 1,664 & 3,426 &, $002^{* *}$ \\
Shoulder from Left Side & $1,304 \pm 1,402$ & $-0,649 \pm 1,504$ & 1,953 & 3,678 &, $001^{* *}$ \\
Hips from Left Side & $1,348 \pm 2,030$ & $-0,346 \pm 2,118$ & 1,694 & 2,236 &, $034^{*}$ \\
Scoliometer & $0,800 \pm 0,676$ & $0,066 \pm 0,457$ & 0,734 & 3,479 &, $002^{* *}$ \\
\hline
\end{tabular}

$* \mathrm{P}<0,05 \quad * * \mathrm{P}<0,01$

In the comparison of the differences of upper extremity measurements of the subject and control groups before and after the study according to the table, in the measurements of shoulder from the anterior side, hips from the anterior side, head from the posterior side, the rib cage from the posterior side, the head from the right side, the head from the left side, shoulder from the left side and scoliometer, a difference in a positive way was determined according to the $\mathrm{p}<0,01$ significance level. In the measurements of the rib cage from the anterior side, the hips from the posterior side, the hips from the left side, a difference in a positive way was determined according to the $p<0,05$ significance level. No statistical difference was determined in the measurements of the head from the anterior side, the shoulder from the posterior side and the hip from the right side.

\section{Discussion}

In this study, what was aimed at is researching the effect of the core exercises applied on the young males between the ages of 16 and 18 for 8 weeks on the upper extremity posture structures. The findings obtained have been discussed in the framework of the literature. Random subject and control groups were formed out of the group of 30 sedentary individuals between the ages of 16-18 that participated in the study, the height, weight, the body mass index and posture imperfections were measured before and after the study, and their comparisons were statistically carried out.

In the study, the upper extremity measurements of the subject and control groups before and after the study were made and they were statistically compared. A literature research about the subject was made; studies that support the study that we have carried out have been found. Nitzschke and his friends have determined that in children with pathological kyphosis, the rate of not doing sport is high. In the research, two groups, one of whom did sport and the other of whom didn't, were compared and while the group doing sport were close to the standard posture, it was determined that there were postural imperfections in the other group. In the light of this information, it was determined that sport has a positive effect on posture (Nitzschke E, Hildenbrand M, 1990). In Celebi's thesis where he compared the postural attributes of students between the ages of 12 and 14 that did sport and those of sedentary students, it is thought that students who actively do sports have a posture close to the standard and as a result of this, sport has a corrective effect on posture. While sport contributes to the standard posture, it needs to be done regularly and systemically (Çelebi F, 2000). Stanton and his friends have made a lot of research on the development of the core region strength in order to "increase the performance", in the realization of sportive success. Abdominal muscles at the front part of the body, back muscles at the back, diaphgram muscles in the upper part and pelvic floor muscles in the bottom part comprise the core region. Hence, if the core region is strong, it protects the spine and enables the posture to be normal (Stanton, Reaburn, 
Humphries, 2004). Koz and his friends state that if the core is strong, this might be important to "preventing injuries in sport", the control of the body, normality of posture and the development of its balance (Koz, Ersöz, 2010). Simsek and Erhan have discovered that physical activities and trainings done regularly whether at a low or high violence have a positive impact on also other systems that have a role in the balance control, particularly on the proprioceptive system (Şimşek, Ertan, 2011). According to Sirmen and his friends, the body makes more than one muscle work during muscle work in order to keep the balance and help one action be done;as a result of this, a standard stance is obtained. Normal joint movements, tests for muscle shortness, planes, anatomical positions and axes constitute the basic structure of posture analysis (Sirmen, Peker, Elmas, 2002). According to Kendall and his friends, a wrong posture affects negatively only the opinions about the physical appearance if it is just an aesthetical problem. However, resistant postural imperfections might cause disturbances, pains and disablements. Normal actions done in the right way, but in a great number, repeated actions done in an inappropriate posture and abnormal actions cause functional imperfections (Kendall, Mcceary, Provance, 1993). Early diagnosis in scoliosis is important not only to preventing deformities likely to form in time and finding and eradicating factors that accelerate its development, but also to treating it with low cost and without the need for surgical intervention. The results of the examined studies indicate that applications of exercise are an effective method for treating mild and moderate scoliosis suffered by adolescent children (Öcal. 2018). It has been determined that doing trainings in a particular branch of sport for a long period of time affects the dynamic and static posture development of sportspeople profoundly; therefore, the planning of exercises should be done in the right way (Kayacan, Makarac1, 2017). As supported in literature research, as core exercises particularly strengthens the muscles in the central abdominal region and in the region of the back, they contribute positively to the upper extremity posture structure.

In conclusion, exercises done regularly that are aimed at strengthening the center of the body make a positive impact on the correction of posture imperfections particularly in individuals in the developmental stage. Sedentary lifestyle, regarded as one of the greatest problems of young individuals in our age, brings with it postural imperfections. These imperfections don't appear all of a sudden, they form slowly and if at an advanced stage, might cause important health problems. The fact that applying core exercises is easy and that they can be applied anywhere and also the fact that they play an effective role in correcting postural imperfections make it absolutely necessary to incorporate them into daily life. Also in our study, it was determined that core exercises are effective in correcting postural imperfections.

\section{References}

Atan, T. (2013). Effect of jogging and core training after supra maximal exercise on recovery. Turkish Journal of sport and exercise. 15(1), 73-77.

Brungardt, K., Brungardt, B., \& Brungardt, M. (2006). The Complete of bookcore Training. Harpercolins Special markets department. Newyork.

Cailliet, R. (1994). Syndromes of Waist Pain, Istanbul, Nobel Publication, 1(36), 37-56.

Çelebi, F. (2000). The Comparison of Postural and Biomotor Attributes of Students between 12-14 years of age in the Puberty Period Engaged in Sport and Sedentary Students, MA thesis, Muğla University, Muğla.

Ecerkale, Ö. (2006). Evaluation of the Results of Symmetry graph and Orthoroent genogram in Posture Analysis, Istanbul.

Elliott, B. (1998). Training in Sport, applying sport science, John Wiley \& Sons Ltd. England, 145-14.

Fig, G. (2005). Strength training for swimmers: Training the core, Strength and conditioning Journal, 27(2), 40-42. https://doi.org/10.1519/00126548-200504000-00008

Gökhan, İ., Aktaş, Y., \& Aysan, H. A. (2015). The Examination of the Relationship between Leg Strength and Speed Values in Amateur Footballers. International Journal of science culture and sport, 4, 49-50.

Hopkins, B. (2014). Validity of posture screen Mobile in the measurement of standing posture.

Karakuş, S., \& K1lınç, F. (2006). Posture and Sportive Performance, Kastamonu Educational Journal, 14(1), 309-322.

Kayacan Y., \& Makarac1, Y. (2017). The Postural Analysis of Handballers through Computer-Based Symmetrigraph Method, The Journal of Sport and Performance Research, 8(1), 32-42.

Kendall, F. P., Mcceary, E. K., \& Provance, P. G. (1993). Muscles testing and function. Pp. Lippincott Williams and wilkins, USA, 71, 84-101.

Kılınç, F. (1997). The Analysis and Synchresis of Postural and Biomotor Attributes of Basketballers in the Puberty and Adolescence Period and of Sedentaries, MA thesis, Marmara University, İstanbul.

Koz, M., \& Ersöz, G. (2010). The Importance of Physical and Muscular Appropriateness in the Prevention of Sport 
Injuries, Orthopedics and Traumatology, 3(1), 14-19.

Nitzschke, E., \& Hildenbrand, M. (1990). Epidemiology of kyphosis in schoolchildren, orthopihregrenzgeb, 128(5), $477-481$.

Normand, M. C., et al. (2007). Three dimensional evaluation of posture in standing with the posture print: an intra-andinter-examiner reliability study. Chiropractic \& $\quad$ osteopathy, $15, \quad 1-12$. https://doi.org/10.1186/1746-1340-15-15

Öcal, D. (2018). The Importance of Medical School Screening in Children with Scoliosis and the Activity of Exercise Treatment, Sports Science, 9, 134-145.

Şimşek, D., \& Ertan, H. (2011). Postural sensory-motor strategies directed at Sport Branches and Postural Oscillation, The Magazine of Physical Training and Sports Sciences, 9(3), 110-132.

Sirmen, B., Peker, Ç., \& Elmas, O. (2002). Postural and Motoric Attributes in Swimmers between the Ages of 12 and 14. 7. International Sports Science Congress Proceedings Book, 588 Antalya/Turkey.

Stanton, R., Reaburn, P. R., \& Humphries, B. (2004). The effect of short-term swiss ball training on corestability ve runningeconomy. The Journal of Strength \& conditioning research, 18(3), 522-528.

Uetake, T., \& Ohtsuki, F. (1993). Sagittal configuration of spinal curvature line in Sportsmen Using moiretechnique, 70(2-3), 91-103.

Wojtys, E. M., Ashton-Miller, J. A., Huston, L. J., \& Moga, P. J. (2000). The association between athletic Training Time and the sag ittalcur vature of the immaturespine, Am J Sports Med, 28(4), PMID: 10921639, $490-8$. https://doi.org/10.1177/03635465000280040801

Yaman, O., \& Dalbayrak, S. (2013). Idiopatic Scoliosis, Turkish Neurosurgery Journal, 23(2), 37-51. 
The List of Core Exercise Actions-- Expositional

\begin{tabular}{|c|c|}
\hline 1.1 & $\begin{array}{l}\text { MOVEMENT: In a position of lying flat, hands strained by the side of } \\
\text { the hip, legs strained and lying at an angle of } 45 \text { degrees, in a position } \\
\text { where the chin touches the upper tip of the sternum, eyes on the navel. } \\
\text { The action of pressing and pulling back is applied as though there was a } \\
\text { small ball under the hands. Inhalation and exhalation at the action of the } \\
\text { hands down and up. } \\
\text { IMPACT: Breath coordination, abdominal region strength }\end{array}$ \\
\hline & $\begin{array}{l}\text { MOVEMENT: Arms lying down, feet on ground and knees strained. } \\
\text { While lying flat, move in the way that vertebrae will touch the ground one } \\
\text { by one; the arms will be in air while the back is on the ground; the chin } \\
\text { will be pressed on the upper tip of the sternum and overlook the navel } \\
\text { while getting up from the ground; the vertebrae will leave the ground one } \\
\text { by one. After the arms lie parallel to the ground, change again to the } \\
\text { position where you lie flat. } \\
\text { IMPACT: Spine mobility, flexibility }\end{array}$ \\
\hline $\mathrm{CH}$ & $\begin{array}{l}\text { MOVEMENT: Start the action with the back lying flat, the chin pressed } \\
\text { on the upper tip of the sternum, knees pulled towards the chest, hands on } \\
\text { the ankles. Afterwards, direct your hands up and your feet into } 45 \text { degrees } \\
\text { and then again change into the starting position. } \\
\text { IMPACT: Abdominal region strength, coordination, breath }\end{array}$ \\
\hline 4. SWIMM & $\begin{array}{l}\text { MOVEMENT: Face down, arms pointing at the opposite direction, feet } \\
\text { lying and pointing at the reverse direction. Carry out the swimmer action } \\
\text { in a strained way, moving arms and legs by using one at a time and the } \\
\text { other at the other side at the same time. } \\
\text { IMPACT: Trapeze, muscular strength of lateral and gluteal region, } \\
\text { coordination }\end{array}$ \\
\hline
\end{tabular}




\begin{tabular}{|c|c|}
\hline $\begin{array}{l}\text { 5. PUSH-UP TRICEPS } \\
\text { PRESS }\end{array}$ & $\begin{array}{l}\text { MOVEMENT: Hands in the width of the shoulders and open, face down, } \\
\text { heels touching each other. Approximate the chest to the ground in a way } \\
\text { that elbows will touch the rib cage while doing push-up and change into te } \\
\text { starting position again. } \\
\text { IMPACT: Triceps and muscular strength on the back region }\end{array}$ \\
\hline 6. SHOULDER BRIDGE & $\begin{array}{l}\text { MOVEMENT: Lying flat, knees bent, soles pressing on the ground, legs } \\
\text { open in the width of shoulders, hands strained by the side of the hips and } \\
\text { shoulders fixated on the ground. Lift your hips onto the air and lower } \\
\text { them in a way that vertebrae will touch the ground one by one. Lift your } \\
\text { hips onto the air again as soon as the sacrum touches the ground. } \\
\text { IMPACT: Spine mobility, abdominal region strength, breath }\end{array}$ \\
\hline 7.PLANK & $\begin{array}{l}\text { MOVEMENT: Face down, elbows on the ground, feet open in the width } \\
\text { of shoulders, only elbows and feet touching the ground. Wait with your } \\
\text { hips tight. } \\
\text { IMPACT: The strength of the muscles where the whole body acts as a } \\
\text { stabilizator. }\end{array}$ \\
\hline 8.SIDE PLANK & $\begin{array}{l}\text { MOVEMENT: Touching the ground with one elbow, the body sideward } \\
\text { and vertical to the ground, the other arm in the air, strained. Hold in this } \\
\text { way. } \\
\text { IMPACT: The strength of stabilizator muscles }\end{array}$ \\
\hline
\end{tabular}

\section{Copyrights}

Copyright for this article is retained by the author(s), with first publication rights granted to the journal.

This is an open-access article distributed under the terms and conditions of the Creative Commons Attribution license which permits unrestricted use, distribution, and reproduction in any medium, provided the original work is properly cited. 